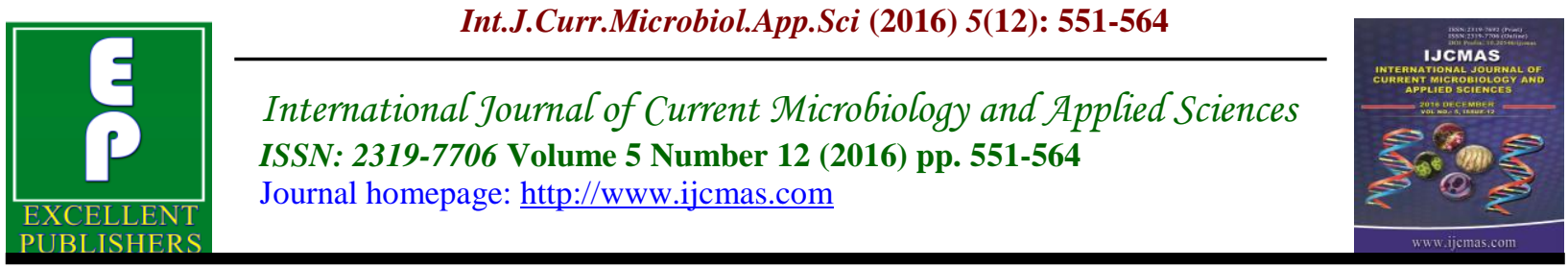

Original Research Article

http://dx.doi.org/10.20546/ijcmas.2016.512.061

\title{
Enhanced Production of $\beta$-glucosidase by New Strain Aspergillus protuberus on Solid State Fermentation in Rice Husk
}

\author{
P. Suresh Yadav, K. Shruthi, B.V. Siva Prasad and M. Subhosh Chandra* \\ Department of Microbiology, Yogi Vemana University, Kadapa-516 003, India \\ *Corresponding author
}

\begin{abstract}
A B S T R A C T
Keywords

Rice husk,

$\beta$-Glucosidase,

Aspergillus

protuberus,

Solid state

fermentation,

Agro residues.

Article Info

Accepted:

18 November 2016

Available Online:

10 December 2016

The potential production of $\beta$-glucosidase by new strain Aspergillus protuberus under solid state fermentation was studied. Cultural and nutritional factors affecting $\beta$-glucosidase production were also investigated in order to optimize the fermentation conditions for the maximization of production. Different fermentation parameters such as different solid substrates, carbon and nitrogen sources, initial $\mathrm{pH}$, moisture content, temperature, and optimized medium on $\beta$-glucosidase production were investigated. Rice husk served as the best solid support for maximal production of $\beta$-glucosidase. A maximum $\beta$-glucosidase production 26.06 $\mathrm{U} / \mathrm{g}$ of rice husk was achieved under optimal conditions such as $1 \%$ glucose, $2 \%$ ammonium sulfate, $\mathrm{pH} 3,40 \%$ moisture content, $30^{\circ} \mathrm{C}$ temperature. An approximately 6 -fold increase in $\beta$-glucosidase production was achieved in the optimized medium as compared with the nonoptimized medium. These results indicate that $\beta$-glucosidase production could be improved using these kind of processes. Also, taking into consideration locally available cheap substrates, economic side of the route is justified.
\end{abstract}

\section{Introduction}

Agricultural, forests and agro-industrial practices are among the causes of environmental pollution. Renewable lignocellulosic biomass, besides being cheap and abundant, has also the advantage that it does not compete with food production. Active efforts were being made to convert these lignocellulosic resources into either glucose or alcohol, and use this either as fuel or as valuable products (Kumakura et al., 1988). Saccharification of polysaccharides to glucose by microbial hydrolytic enzymes which had attracted the attention of the researchers, as this was the first step of bioconversion of lignocellulosic material into valuable products such as sugar, fine chemicals and biofuels (Howard et al., 2003). As the cost of cellulosic substrates play the central role in determining the economy of the saccharification process, lot of emphasis had been given to the usage of low price substrates and therefore screening of the agricultural wastes for release of sugars as organic wastes from renewable forest and agricultural residues (Heck et al., 2002). The saccharification of different agro wastes had been reported by other workers employing enzymes from various organisms (Katzen and Fowler 1994; Van Wyk and 
Leogale 2001; Baig et al., 2004; Chandra et al., 2007). ß-Glucosidases (ß-D-glucoside glucohydrolase, E.C. 3.2.1.21), under physiological conditions, catalyze the hydrolysis of $\beta-1,4$-glycosidic bonds from the non-reducing termini presented in alkyland aryl- $\beta$-D-glycosides, as well as different oligosaccharides (containing 2-6 monosaccharides). The deficiency in $B$ glucosidase activity causes the accumulation of the disaccharide cellobiose, leading to the repression of enzyme biosynthesis and endproduct inhibition of the upstream enzymes, which result in a limited hydrolysis yield (Zaldivar et al., 2001). Therefore, commercially available cellulolytic preparations are often supplemented with $\beta$ glucosidase to boost the overall activity, such as that prepared from Trichoderma reesei cellulases (Chauve et al., 2010). BGlucosidase is the rate-limiting factor in the conversion of cellulose to glucose for the subsequent production of fuel ethanol.

B-Glucosidases have been the subject of interest in recent research due to their potential for many biotechnological applications in food products, pulp and paper, jams, juices, biomass conversion and pollution control (Tolan and Foody, 1999). These enzymes can be recovered easily from SSF, making this system extremely appropriate for protein enrichment and cellulase production from lignocellulosics (Kim et al., 1985). In general, the industrial applicability of an enzyme is closely related the cost of its production and physicochemical characteristics. The production costs can be reduced by screening hyper producer strains, associated with the cultivation process optimized in low-cost mediums (Leite et al., 2008). The objective of this research was to evaluate the B-glucosidase production by $A$. protuberus and to determine the influence of some parameters to maximize the production of this enzyme.

\section{Materials and Methods}

\section{Culture and Preparation of Inoculum}

Aspergillus protuberus isolated from the decaying Mahanandi forest litter soils was maintained on Czapek Dox medium and spore suspension was prepared from 7 days grown old slants by adding adequate amount of sterile distilled water with Tween-20 $(0.2 \%, \mathrm{v} / \mathrm{v})$. This fungal culture was maintained on Czapek Dox medium.

\section{Lignocellulosic Substrates}

Lignocellulosic substrates such as castor husk, sugarcane bagasse, sesame husk, groundnut fodder, rice husk, tea residue, sorghum husk and sawdust were chosen as solid matrices for use in solid state fermentation in this study because of their abundance in the local area at cheaper rates. Groundnut fodder, castor husk, cane bagasse and tea residue were collected from local farmers whereas rice husk and sawdust were obtained from rice mill and saw mill in Kadapa respectively. Sesame husk and sorghum husk were collected from farmers in Nandyal, Kurnool District. The substrates were individually sieved through a $2 \mathrm{~mm}$ screen, for uniform particle size.

\section{Solid State Fermentation (SSF)}

Solid state fermentation (SSF) was carried out in $250 \mathrm{ml}$ Erlenmeyer flasks. Ten grams of different lignocellulosic substrates were dispensed. One liter of Czapek Dox liquid medium contained $\mathrm{NaNO}_{3}-2.0 \mathrm{~g}, \mathrm{~K}_{2} \mathrm{HPO}_{4}$ $1.0 \mathrm{~g}, \mathrm{MgSO}_{4} \cdot 7 \mathrm{H}_{2} \mathrm{O}-0.5 \mathrm{~g}, \mathrm{KCl}-0.5 \mathrm{~g}$, $\mathrm{FeSO}_{4} \cdot 7 \mathrm{H}_{2} \mathrm{O}-0.01 \mathrm{~g}$, Sucrose $-30.0 \mathrm{~g}$ and Cellulose - 5.0 g. The different lignocellulosic matrices require different volumes of water within a range of $10-15 \mathrm{ml}$ for $50 \%$ moisturization of 10-gram samples. Each flask was covered with hydrophobic cotton and autoclaved at $121^{\circ} \mathrm{C}$ for $15 \mathrm{~min}$. 
Sterile solid culture medium in the flasks were inoculated with the spores of $A$. protuberus at density of $2 \times 10^{6}$ spores/flask and incubated at ambient temperature $\left(30 \pm 2^{\circ} \mathrm{C}\right)$. At the regular intervals the samples were withdrawn for processing. Entire fermented bran in the flask was mixed with distilled water, the slurry was filtered through muslin cloth and the filtrate was centrifuged at $10,000 \mathrm{rpm}$ for $20 \mathrm{~min}$ at $4^{0} \mathrm{C}$ and the supernatant was used for determination of enzyme activity (Deswal et al., 2011).

\section{Effect of Carbon Source}

To determine the appropriate carbon source for $\beta$-glucosidase production by $A$. protuberus normal Czapek Dox medium was supplemented with different carbon compounds (glucose, lactose, sucrose, fructose and maltose at concentration of $1 \%$ level. The supplemented medium was used to moisten the rice husk. Cultivation of $A$. protuberus was carried out in the same manner as specified above. The best carbon source was further amended at different concentrations to the normal Czapek Dox medium to find out optimal concentration for production of $\beta$-glucosidase.

\section{Effect of Nitrogen Source}

To determine the appropriate nitrogen source for $\beta$-glucosidase production by $A$. protuberus normal Czapek Dox medium was supplemented with six nitrogen compounds (sodium nitrate, urea, ammonium sulphate, peptone, beef extract and yeast extract at concentration of $1 \%$ level. The supplemented medium was used to moisten the rice husk. Cultivation of $A$. protuberus was carried out in the same manner as specified in SSF. The best nitrogen source was further amended at different concentrations to the normal
Czapek Dox medium to find out optimal concentration for production of $\beta$ glucosidase.

\section{Effect of pH}

In order to determine the most suitable $\mathrm{pH}$, the fermentation Czapek Dox medium was adjusted to different $\mathrm{pH}$ in the range of $\mathrm{pH}$ $3.0-6.0$ using $0.1 \mathrm{M} \mathrm{HCl}$ and $0.1 \mathrm{M} \mathrm{NaOH}$. Adjusted medium was used to moisten rice husk. A. protuberus was cultivated on rice husk in the manner as specified in SSF.

\section{Effect of Moisture Content}

To determine the optimum moisture content in the fermentation process for maximal production of $\beta$-glucosidase, only five milliliters of the normal Czapek Dox medium was added to the $10 \mathrm{~g}$ rice husk in the flasks at the beginning, and the remaining balance for achieving desired moisture level was provided to the respective matrix in the form of distilled water (Chandra et al., 2008). Thus moisture content of the fermentation medium varied from $20-80 \%$. A. protuberus on rice husk with different moisture levels was cultivated in the manner as specified in SSF.

\section{Effect of Temperature}

In order to determine the effective growth temperature for $\beta$-glucosidase production by A. protuberus the fermented medium was incubated at temperature in the range of 25 $40^{\circ} \mathrm{C}$. Rice husk was incubated out after inoculation.

\section{Formulation of Optimized Medium for Production of $\beta$-Glucosidase}

Czapek Dox medium was amended with carbon, nitrogen sources and $\mathrm{pH}$ in the right proportion in accordance with the results of 
earlier experiments for enhanced production of $\beta$-glucosidase. The medium contained $\begin{array}{lllll}(\mathrm{g} / \mathrm{L}) & \mathrm{NaNO}_{3} & 2.0, & \mathrm{~K}_{2} \mathrm{HPO}_{4} & 1.0 \text {, }\end{array}$ $\mathrm{MgSO}_{4} .7 \mathrm{H}_{2} \mathrm{O} \quad 0.5, \mathrm{KCl} \quad 0.5, \mathrm{FeSO}_{4} .7 \mathrm{H}_{2} \mathrm{O}$ 0.01, Glucose 10, Cellulose 5.0, $\left(\mathrm{NH}_{4}\right)_{2} \mathrm{SO}_{4}$ 20, Distilled water $1000 \mathrm{ml}, \mathrm{pH}$ 5.0. The optimized Czapek Dox medium was used to moisten the solid substrate-rice husk in subsequent experiments conducted.

\section{$\beta$-Glucosidase Assay}

$\beta$-Glucosidase activity was determined by reducing $P$-Nitro phenyl $\beta$-D-gluco pyranoside (PNPG) under acidic conditions (Herr 1979). For the determination of $\beta$ glucosidase activity in the assay mixture contained $0.2 \mathrm{ml}$ of $5 \mathrm{mM} P$-Nitro phenyl $\beta$ D-gluco pyranoside (PNPG) in $1 \mathrm{ml}$ of 0.05 $M$ citrate buffer (pH4.8) and $0.5 \mathrm{ml}$ of enzyme source was added and incubated at $50^{\circ} \mathrm{C}$ for 30 mins. After incubation the reaction was stopped by adding $4 \mathrm{ml}$ of 0.05 $\mathrm{M} \mathrm{NaOH}$ Glycine buffer ( $\mathrm{pH}$ 10.6) and the yellow color $P$-Nitrophenol liberated was determined at $420 \mathrm{~nm}$ by using Spectrophotometer (Shimadzu). One unit of $\beta$-glucosidase activity is defined as the amount of enzyme liberating $1 \mu$ mole of $p$ nitro phenol per min under standard assay conditions.

\section{Statistical Analysis}

Data presented are the averages of replicates. Duncan's Multiple Range (DMR) test for all data was carried out (Megharaj et al., 1999).

\section{Results and Discussion}

\section{Selection of Substrate for $\beta$-Glucosidase} Production

Selection of a suitable substrate for maximum production of enzyme in SSF is an important parameter. Among the tested solid substrates, the cultivation of $A$. protuberus in both rice husk and castor husk provided higher $\beta$-glucosidase production (3.46 U/g of substrate) and minimum activity ( $0.13 \mathrm{U} / \mathrm{g}$ of substrate) was recorded for sugarcane bagasse (fig 1). Both rice husk and castor showed maximum $\beta$-glucosidase production, but rice husk can be considered because of it's more abundance in our local area due to cultivation of rice in large area.

Higher $\beta$-glucosidase production can be achieved during the culturing of microorganisms in SSF, using rice husk as either the main substrate or as a substantial component of the mixture (Bhatti et al., 2013). The titer of $\beta$-glucosidase production in the present study was higher when compared to the results in the study of Chandra et al., 2007. According to this study, the titer of $\beta$-glucosidase activity (0.0169 U/g of substrate) was obtained from sawdust as solid support. Titer of $\beta$ glucosidase at peak production time interval in SSF were higher on rice husk than on other solid matrices in the present study. Thus, rice husk was selected for subsequent experiments in order to optimize the cultivation process for $\beta$-glucosidase production.

The association of cellulose with lignin and hemicelluloses in the lignocellulosic materials is an important factor limiting the hydrolys ability. Removal/degradation of hemicelluloses and lignin by pretreatments such as alkali or acid or $\mathrm{H}_{2} \mathrm{O}_{2}$ etc., open up the cell wall structure, thus increasing the accessibility of cellulose to cellulases (Zhang and Lynd, 2004). Pretreatment process may improve substrate utilization by the microbes and enhance enzyme yields. In the present study, only native lignocellulosic substrates without pretreatment were used. Use of pretreated lignocelluloses may 
further increase yields of cellulolytic enzymes by microorganisms in SSF and needs to be further explored (Ortega $e t$ al., 2000; Pandey et al., 2000 and Pan et al., 2006).

The effect of carbon sources on the induction of $\beta$-glucosidase production was investigated. Carbon sources tested for induction of $\beta$-glucosidase were glucose, lactose, sucrose, fructose and maltose at a concentration of $1 \%(\mathrm{w} / \mathrm{v})$. As shown in fig. 2 , glucose was found to be the best carbon source for maximum production of $\beta$ glucosidase. Sucrose was the second followed by maltose, fructose and lactose. This result is similar to that of Trichosporon asahii and Fomitopsis pinicola KCTC 6208 (Park et al., 2015 and Wang et al., 2015).

\section{Different Concentrations of Glucose}

Higher yields of $\beta$-glucosidase from fermentation of rice husk with glucose at $1 \%$ $(\mathrm{w} / \mathrm{v})$ used in the present study on $3^{\text {rd }}$ day of incubation (fig. 3). Addition of glucose beyond $1 \%$ level did not result in improvement of yields of $\beta$-glucosidase, in particular, on early incubation time $\left(1^{\text {st }}\right.$ day) and caused decrease in activity of $\beta$ glucosidase

The presence of glucose in the fermentation medium was found to be the most effective for production of glucanase, as well as for production of cellulolytic enzymes by $T$. viride. On the other hand sucrose induced cellobiase better than glucose in the same organism. But, glucose induced FPase better than sucrose in other organism $P$. chrysogenum on lignocellulosics in SSF condition. Among the different concentrations of glucose tested in the present study, $1.0 \%$ of glucose served as the best concentration followed by maltose, sucrose, fructose and lactose for $\beta$ glucosidase production.

\section{Effect of Nitrogen Sources on $\beta$ - Glucosidase Production}

To optimize the nitrogen sources, various nitrogen sources including sodium nitrate, ammonium sulfate, urea, peptone, beef extract and yeast extract were tested in a same concentration $(1 \% \mathrm{w} / \mathrm{v})$. Fig 4 showed that maximum activity of $\beta$-glucosidase at ammonium sulfate as a nitrogen source. Sodium nitrate showed second highest for $\beta$ glucosidase activity followed by peptone, beef extract, yeast extract and urea.

Generally, microorganisms exhibit diversity in metabolic patterns in utilization of nitrogen sources. Badhan et al., 2007 could achieve the optimal level (8 U/gds) of $\beta$ glucosidase activity by Myceliophthara sp. on combination of $\mathrm{CH}_{3} \mathrm{COONH}_{3} 0.35 \%$, $\left(\mathrm{NH}_{4}\right)_{2} \mathrm{SO}_{4} \quad 0.7 \%$ and $\mathrm{KH}_{2} \mathrm{PO}_{4} \quad 0.4 \%$. Introduction of ammonium sulphate at $2 \% \mathrm{~N}$ $(w / w)$ enhanced extracellular soluble protein/g of substrate by A. niger in comparison to control by about $13.6 \%$ (Fadel 2000). This increase in soluble proteins was accompanied by increase to the extent of 21.3, 21.5 and $20 \%$ in the activity of FPase, CMCase and $\beta$-glucosidase respectively. Spiridonov and Wilson (1998) showed that $\mathrm{NH}_{4}$ compounds were the most favorable nitrogen sources for production of protein and cellulase. Similarly, among nitrogen sources tested in the present study, ammonium sulphate served the best nitrogen source on the basis of yields of FPase, CMCase and $\beta$-glucosidase. The results of the present study were in conformity with observation made by other studies on the same or different organisms (Chahal et al., 1996; Krishna 1999; Park et al., 2002 and Badhan et al., 2007). 
The observations of Ilyas et al., 2002 reported maximum cellulase activity with ammonium sulphate as nitrogen source which supports the result of the present study conducted. The efficiency of ammonium sulphate as nitrogen providing source may be due to its direct availability as nitrogen source for protein production (Mandals 1975).

\section{Different Concentrations of Ammonium sulfate}

Ammonium sulphate was found to be the best nitrogen source for production of $\beta$ glucosidase by $A$. protuberus according to the results of the previous experiment. $\left(\mathrm{NH}_{4}\right)_{2} \mathrm{SO}_{4}$ was tried only at $1 \%(\mathrm{w} / \mathrm{v})$ concentration in that experiment. Dose response of ammonium sulphate supplementation within a range of 0.5 $2.5 \%$ on production of $\beta$-glucosidase by $A$. protuberus was examined (fig 5). Maximum $\beta$-glucosidase activity with $26.34 \mathrm{U} / \mathrm{g}$ of rice husk was observed in the rice husk amended with $2.0 \%$ of ammonium sulphate on $5^{\text {th }}$ day of incubation followed by 25.42 at $0.5 \%$ concentration of ammonium sulphate amended medium on $5^{\text {th }}$ day of incubation.

Additional supply of nitrogen has been reported by various scientists to enhance the growth of the microbes and their physiology (Fan et al., 1981; Yadav 1987 and Garg 1990). Ammonium salts in form of sulphate was found to facilitate higher production of cellulolytic enzymes by Penicillium funiculosum, Myrothecium sp., A. terreus (Harima et al., 1980; Rao et al., 1985 and Chahal et al., 1996). Additional supply of ammonium sulphate to nitrogen deficient rice straw/wheat straw supported higher growth and high enzyme activity in Aspergillus niger as well as thermophilic fungal strains Thermoascus aurantiacus and Myceliophthora sp. (Kalogeris et al., 1998;
Park et al., 2002 and Badhan et al., 2007). Over all, on the basis of all together $\left(\mathrm{NH}_{4}\right)_{2} \mathrm{SO}_{4}$ at $2.0 \%$ was considered as optimal concentration of nitrogen source for higher production of $\beta$-glucosidase by $A$. protuberus.

\section{Effect of pH}

Maximum $\beta$-glucosidase activity $(2.35 \mathrm{U} / \mathrm{g}$ of substrate) was observed at $\mathrm{pH}$ of 5 (fig 6). The $\beta$-glucosidase production by $A$. protuberus was affected when $\mathrm{pH}$ level was higher or lower than the optimum value of $\beta$-glucosidase production. The similar results were reported by Garcia (Garcia et al., 2002). Most filamentous fungi show optimal growth in slightly acidic $\mathrm{pH}$. The $\mathrm{pH}$ was not controlled during the cultivation process due to the heterogeneity of the process of SSF. According to Pandey et al., 2000 the difficulty of monitoring and controlling fermentation parameters in SSF is perhaps, the main drawback of this process. Variations of $\mathrm{pH}$ during the fermentation process are due to the metabolic activity of the microorganisms, and may be increased or decreased according to the by-products released or the nutrients consumed during the process.

The fungus $A$. niger expressed high cellulase production on agro-residues at initial $\mathrm{pH} 4.5$ - 5.5 in SSF (Wang et al., 2012). Maximum production of $\beta$-glucosidase activity was observed at $\mathrm{pH} 5.0$ by Fusarium proliferatum NRRL 26517 grown on Ficus nitida wastes (Fawzi 2003). The maximum activity of cellulolytic enzymes was obtained when the initial $\mathrm{pH}$ was adjusted to 7.0 for growth of $F$. oxysporum on corn stover (Panagiotou et al., 2003). But in the present study of SSF, A. protuberus was cultivated on rice husk for generation of $\beta$ glucosidase enzyme at pH 5.0. 


\section{Effect of Temperature}

The incubation temperature of the fermentation medium is one of the ultimate factors influencing the production of enzymes. The ideal temperature for $\beta$ glucosidase production by $A$. protuberus was $30^{\circ} \mathrm{C}$, about $3.67 \mathrm{U} / \mathrm{g}$ of substrate (Fig. 7).

The optimum temperature $32^{\circ} \mathrm{C}$ was recorded for the maximum production of cellulolytic enzymes by $A$. niger F-119 on radicle wastes (Fadel 2000). Badhan et al., 2007 showed that the incubation temperature at $45^{\circ} \mathrm{C}$ was found to be optimum for production of cellulolytic enzymes by Myceliophthora sp. IMI 387099. The maximum cellulase yield was obtained at temperature of $28^{\circ} \mathrm{C}$ using Trichoderma reesei (Muthuvelayudham and Viruthagiri 2006). Krishna (1999) observed that the optimal growth and enzyme production were recorded at $35^{\circ} \mathrm{C}$ on banana wastes. Thus, occurrence of optimal production of enzyme at different temperatures may be related to the growth kinetics of the microorganism employed rather than the enzyme produced. In the present study, cultivation of $A$. protuberus in SSF on rice husk with temperature at $30^{\circ} \mathrm{C}$ generated higher production of $\beta$ glucosidase.

\section{Effect of Moisture Content}

Among the moisture contents evaluated, the highest $\beta$-glucosidase production was obtained in rice husk with $40 \%$ of initial moisture on $5^{\text {th }}$ day of incubation (fig 8). The production of $\beta$-glucosidase on rice husk at all moisture regimes was low on the $1^{\text {st }}$ and $2^{\text {nd }}$ day of incubation and increased significantly on $3^{\text {rd }}$ day of the incubation onwards. The highest yield of $\beta$-glucosidase production was recovered $(5.31 \mathrm{U} / \mathrm{g})$ on $5^{\text {th }}$ day of incubation with $40 \%$ moisture level.

Fig.1 Effect of different substrates on production of $\beta$-glucosidase by A. protuberus in SSF.

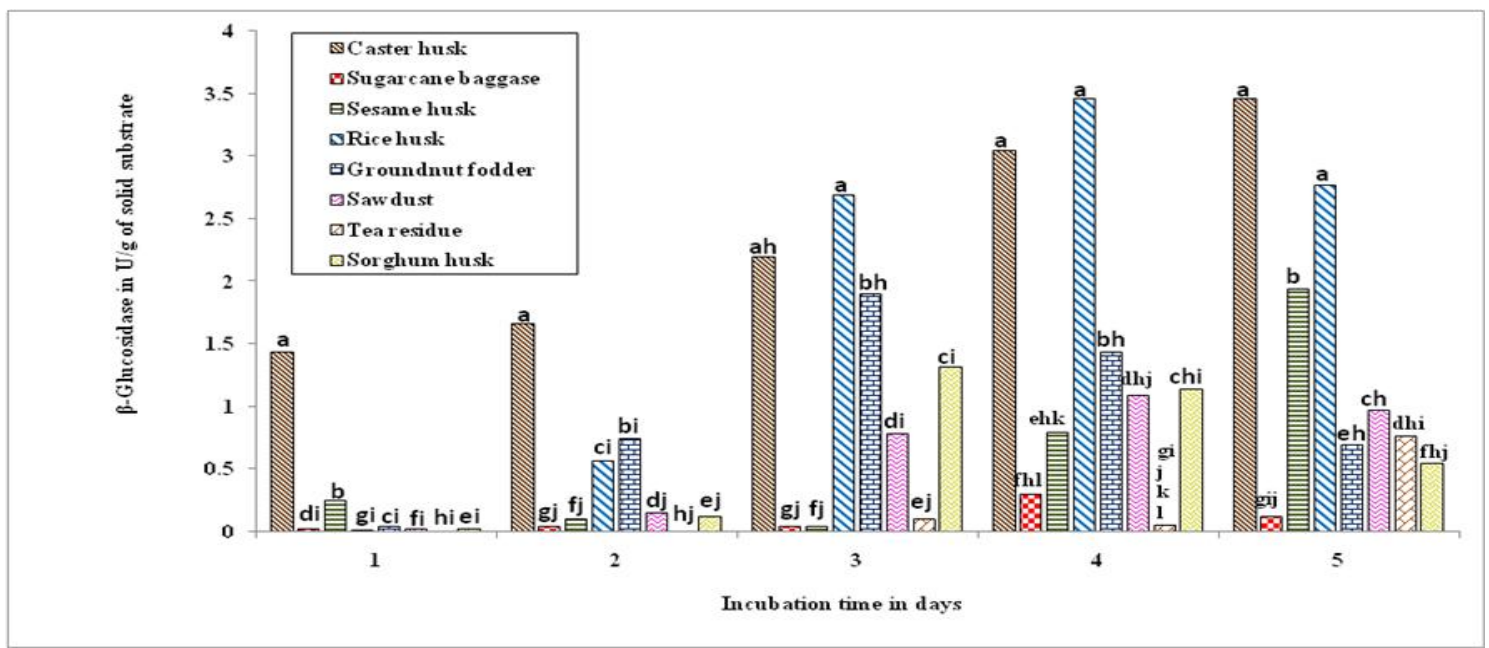

Means, in each column, followed by the same letter are not significantly different $(p \leq 0.05)$ from each other according to DMR test. 
Fig.2 Effect of supplementation of carbon sources on production of $\beta$-glucosidase in rice husk by $A$. protuberus in SSF.

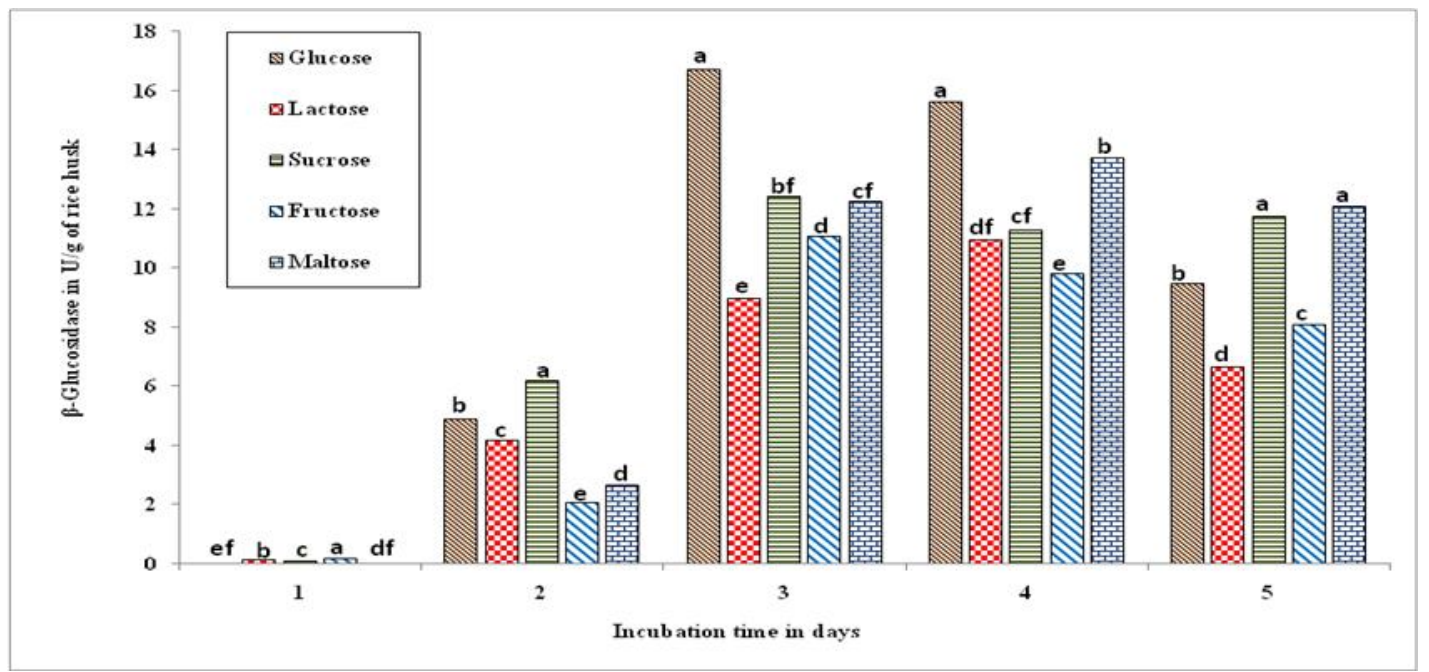

Means, in each column, followed by the same letter are not significantly different $(\mathrm{p} \leq 0.05)$ from each other according to DMR test.

Fig.3 Effect of supplementation glucose on production of $\beta$-glucosidase in rice husk by

A. protuberus in SSF.

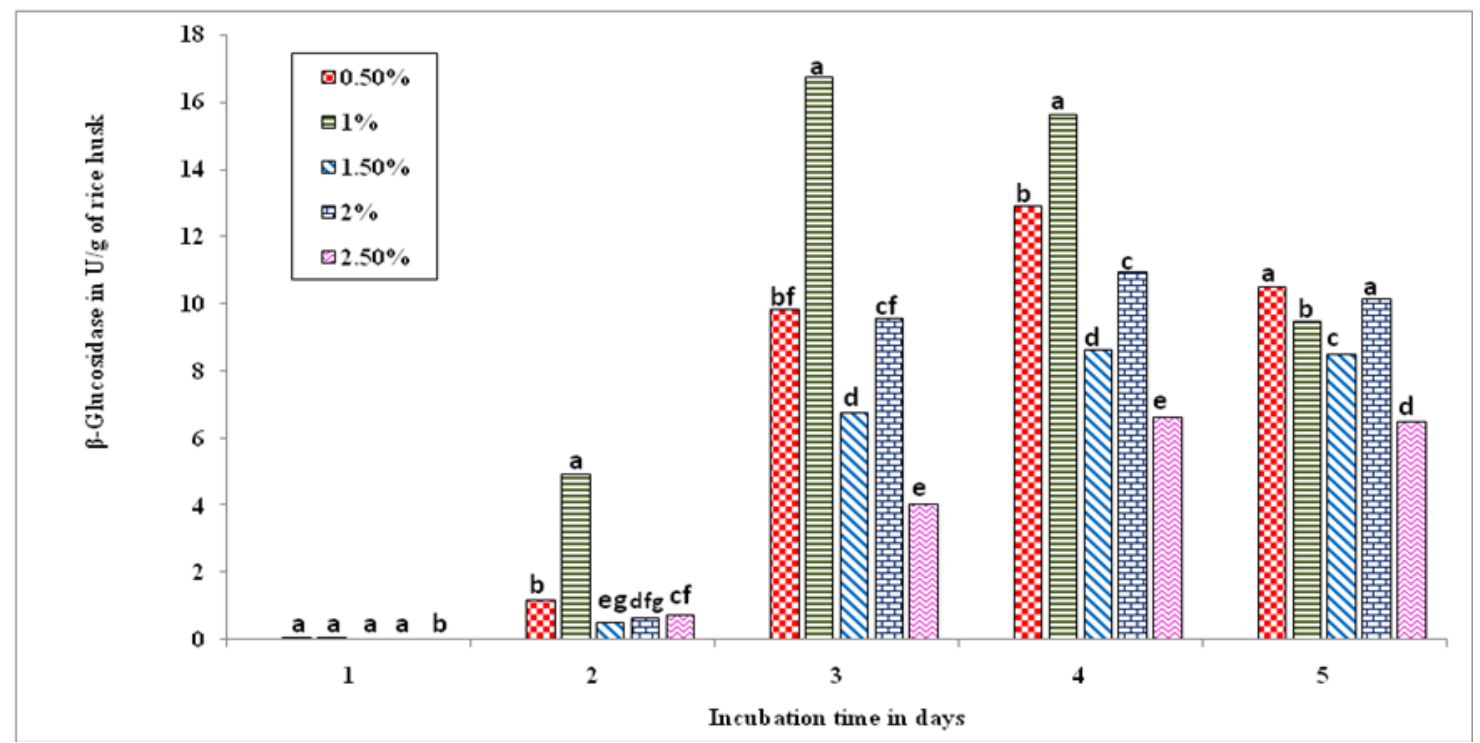

Means, in each column, followed by the same letter are not significantly different $(\mathrm{p} \leq 0.05)$ from each other according to DMR test. 
Fig.4 Effect of supplementation of nitrogen sources on production of $\beta$-glucosidase in rice husk by A.protuberus in SSF.

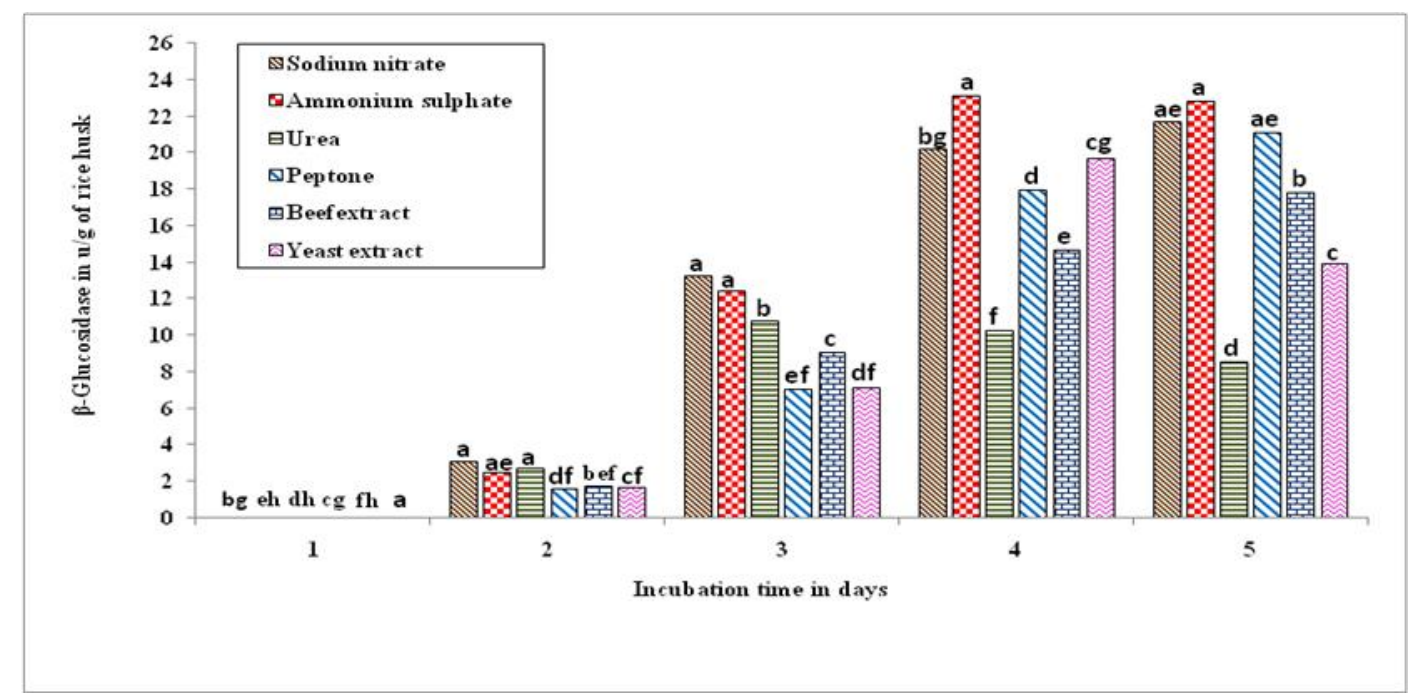

Means, in each column, followed by the same letter are not significantly different $(\mathrm{p} \leq 0.05)$ from each other according to DMR test.

Fig.5 Effect of supplementation of ammonium sulphate on production of $\beta$-glucosidase in rice husk by A.protuberus in SSF.

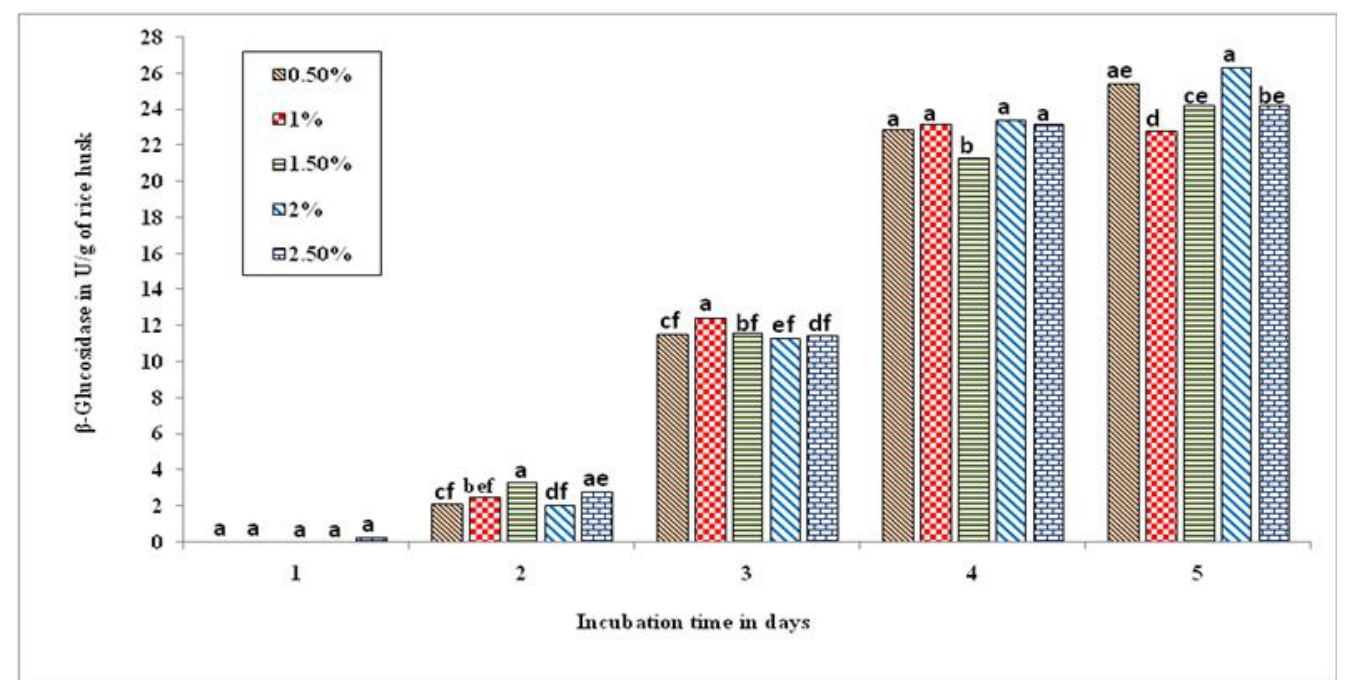

Means, in each column, followed by the same letter are not significantly different $(\mathrm{p} \leq 0.05)$ from each other according to DMR test. 
Fig.6 Effect of initial $\mathrm{pH}$ on production of $\beta$-glucosidase in rice husk by A. protuberus in SSF.

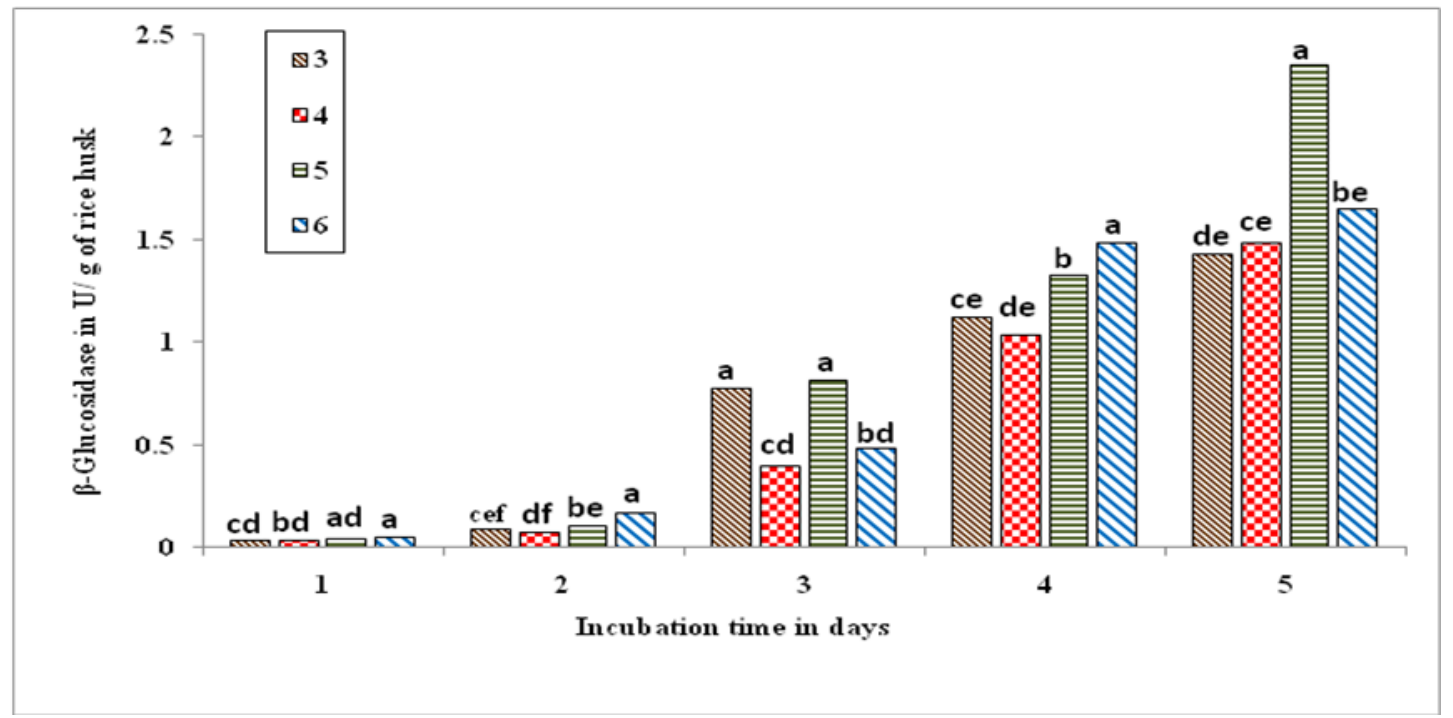

Means, in each column, followed by the same letter are not significantly different $(p \leq 0.05)$ from each other according to DMR test.

Fig.7 Influence of growth temperature on production of $\beta$-glucosidase by A.protuberus in SSF.

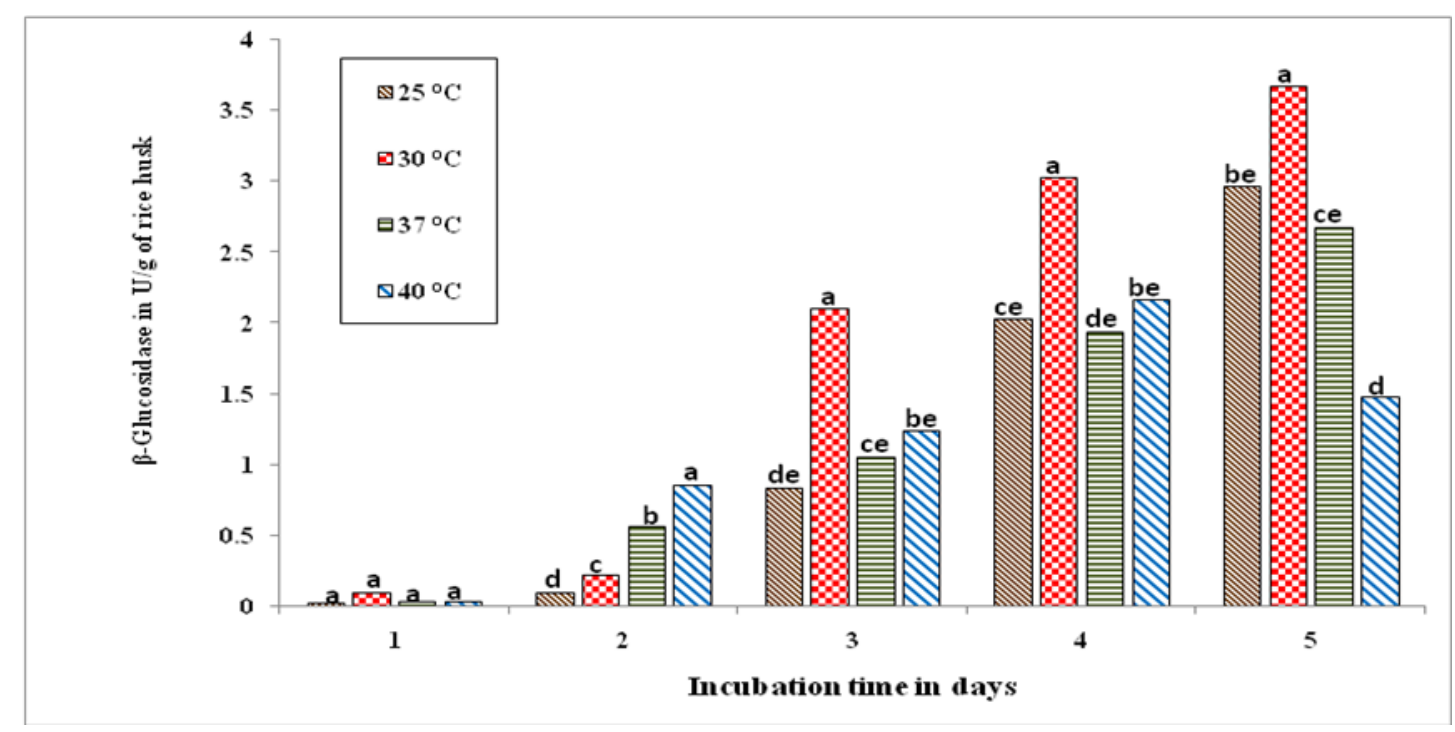

Means, in each column, followed by the same letter are not significantly different $(p \leq 0.05)$ from each other according to DMR test. 
Fig.8 Effect of moisture level on production of $\beta$-glucosidase in rice husk by 3 A.protuberus in SSF.

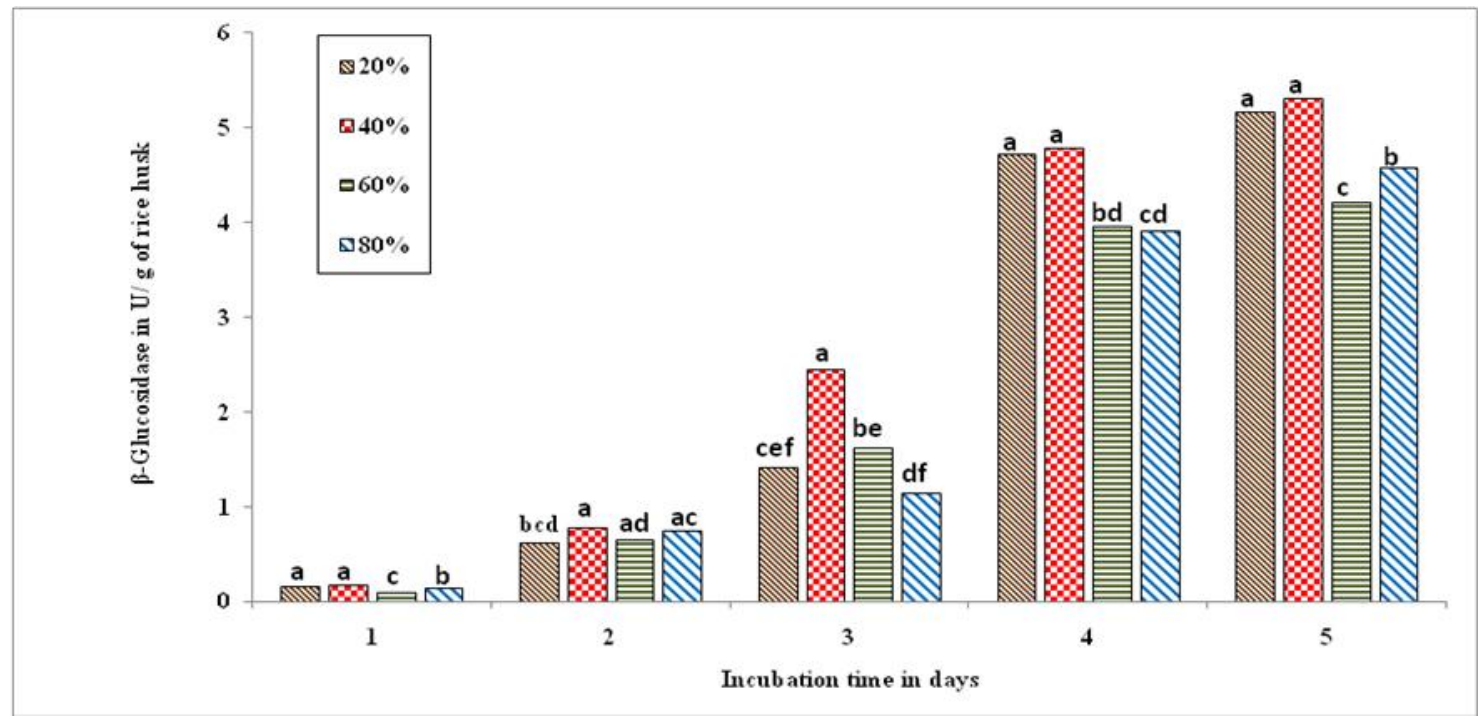

Means, in each column, followed by the same letter are not significantly different $(\mathrm{p} \leq 0.05)$ from each other according to DMR test.

Fig.9 Effect of optimized medium in the production of $\beta$-glucosidase in rice husk by A.protuberus in SSF.

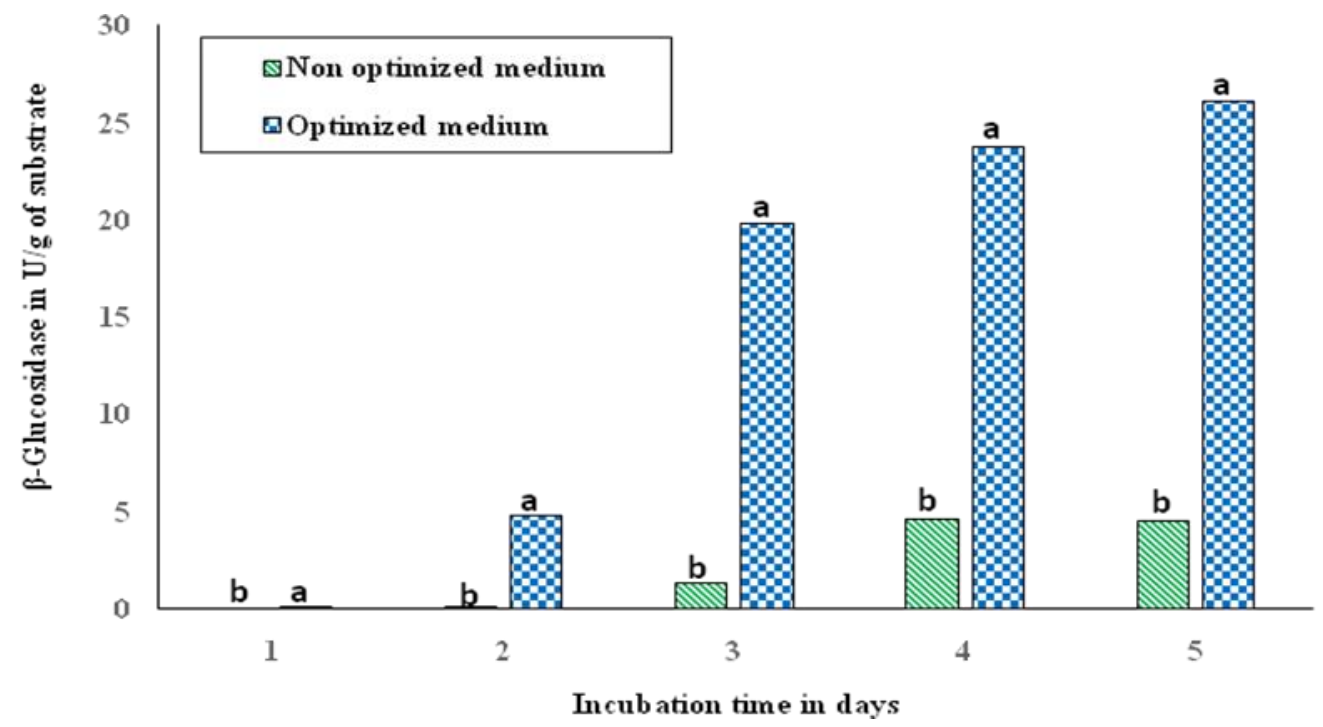

Means, in each column, followed by the same letter are not significantly different $(p \leq 0.05)$ from each other according to DMR test.

The moisture level demands in solid state fermentation differ according to enzyme to be produced, substrate, and microorganism as well as particle size of the substrate as 
well as the configuration of the particles (Nandakumar et al., 1994; Muniswaran et al., 1994 and Krishna and Chandrasekharan 1996).

\section{Effect of Optimized Medium}

The higher $\beta$-glucosidase production 26.06 $\mathrm{U} / \mathrm{g}$ rice husk was recorded at 5th day of incubation in optimized medium whereas in normal Czapek dox medium showed $\beta$ glucosidase production only $4.63 \mathrm{U} / \mathrm{g}$ rice husk at 4th day of incubation (fig 9). By using optimized medium $\beta$-glucosidase production was increased 6 times as compared with non-optimized medium normal Czapek Dox medium.

In conclusion, to the best of our knowledge, there has been no study on $\beta$-glucosidase production from Aspergillus protuberus. Therefore, an attempt was made in this study to maximize the $\beta$-glucosidase production using cheap locally available solid substrate- rice husk in SSF. Recent years, studies on $\beta$-glucosidases are coming more frequent given the key role of this enzyme in ethanol production for biofuels. The cost-effective technologies are needed for the production of enzyme and SSF is a suitable technology for economical production of cellulases using lignocellulosic residues as substrate. Major parameters affecting the fermentation process for enzyme production were studied and optimal levels were identified. It is concluded from the findings that the strategy to produce $\beta$-glucosidase from rice husk was successful as it resulted in a considerably good amount of this enzyme produced (26.06 U/g of rice husk) by newly isolated strain Aspergillus protuberus under optimized conditions.

\section{References}

Badhan, A.K., Chadha, B.S., Kaur, J., Saini, H.S., Bhat, M.K. 2007. Production of multiple xylanolytic and cellulolytic enzymes by thermophilic fungus Myceliophthora sp. IMI 387099. Biores. Technol., 98: 504-510.

Baig, M.M.V., Baig, M.L.B., Baig, M.I.A., Yasmeen, M. 2004. Saccharification of banana agro-waste by cellulolytic enzymes. Afric. J. Biotechnol., 3: 447-50.

Bhatti, H.N., Batool, S., Afzal, N. 2013. Production and characterization of a novel $\beta$-glucosidase from Fusarium solani. Int. .J Agric. Biol., 15: 140-144.

Chahal, P.S., Chahal, D.S., Lee, G.B.B. 1996. Production of cellulase in solid state fermentation with Trichoderma reesei MCG80 on wheat straw. Appl. Biochem. Biotechnol., 57: 433-441.

Chandra, M.S., Rajasekhar, B.R., Yong-Lark Choi. 2008. Optimization of extraction of Filter paperase from the fermented bran of Aspergillus niger in solid state fermentation. J Korean Society Appl. Biol. Chem., 51(4): 155-159.

Chandra, M.S., Viswanath, B., Rajasekhar, B.R. 2007. Cellulolytic enzymes on lignocellulosic substrates in solid state fermentation by Aspergillus niger. Indian J. Microbiol., 47: 323-328.

Chauve, M., Mathis, H., Delphine, H., Dominique, C., $\quad$ Frédéric, M., Nicolas Lopes, F. 2010. Comparative kinetic analysis of two fungal $\beta$ glucosidases. Biotechnol. Biofuel, 3: 3-8.

Deswal, D., Khasa, Y.P., Kuhad, R.C. 2011. Optimization of cellulase production by a brown rot fungus Fomitopsis Sp. RCK2010 under solid state fermentation. Bioresour. Technol., 102: 6065-6072.

Fadel, M. 2000. Production physiology of cellulases and $\beta$-glucosidase enzymes of Aspergillus niger grown under solid state fermentation conditions. J. Biol. Sci., 1(5): 401-411.

Fan, L.T., Lee, Y.H., Beardmore, D.H. 1981. The influence of major structural features of cellulose on rate of enzymatic hydrolysis. Biotechnol. Bioeng., 23: 419 442.

Fawzi, E.M. 2003. Production and purification of beta-glucosidase and protease byFusarium proliferatum NRRL 26517 
grown onFicus nitida wastes. Ann. Microbiol., 53 (4): 463-476.

Garcia, O., Torres, A.L., Colom, J.F. 2002. Effect of cellulase-assisted refining on the properties of dried and never-dried eucalyptus pulp. Cellulose 9: 115-125.

Garg, A.P. 1990. Effect of urea treatment on leaf litter mycoflora of tricale and guar. $J$. Indian Bot. Soc., 69: 89-92.

Harima, T., Humphrey, A. 1980. Estimation of Trichoderma reesei QM 9414 biomass and growth rate by indirect means. Biotechnol. Bioeng., 22: 821-831.

Heck, J.X., Hertz, P.F., Ayub, M.A.Z. 2002. Cellulase and xylanase production by isolated Amazon Bacillus strains using soybean industrial residue based solid state cultivation. Braz. J. Microbiol., 33: (2002) 213-218.

Herr, D. 1979. Secretion of cellulases and $\beta$ glucosides by Trichoderma viride TTCC 1433 in submerged cultures on different substrates. Biotechnol. Bioeng., 21:1361 1363.

Howard, R.L., Abotsi, E., Jansen van Rensburg, E.L., Howard, S. 2003. Lignocellulose biotechnology: issues of bioconversion and enzyme production. African $J$. Biotechnol., 2: 602-619.

Ilyas, U., Abdual Majeed., Hussain, K., Nawaz, K., Ahmed, S., Nadeem, M. 2011. Solid state fermentation of Vigna mungo for cellulase production by Aspergillus niger. World Applied Sci. J., 12 8: 1172-1178.

Kalogeris, E., Chistakopoulos, P., Kekos, D., Macris, B.J. 1998. Studies on the solidstate production of thermostable endoxylanases from Thermoascus aurantiacus. characterization of two isoenzymes. J. Biotechnol., 60: 155-163.

Katzen, R., Fowler, D.E. 1994. Ethanol of lignocellulosic waste with utilization of recombinant bacteria. Appl. Biochem. Biotechnol., 45: 697-707.

Kim, J.H., Hosobuchi, M., Kishimoto, M., Seki T., Yoshida, T., Taguchi, H., Ryu, D.D.Y. 1985. Cellulase production by a solid state culture system. Biotechnol Bioeng., 27: 1445-1450.

Krishna, C. 1999. Production of bacterial cellulases by solid state bioprocessing of banana wastes. Biores. Technol., 69: 231239.

Krishna, C., Chandrasekharan, M. 1996. Banana waste as substrate for $\alpha$-amylase production by Bacillus subtilis (CBTK 106) under solid state fermentation. Appl. Microbiol. Biotechnol., 46: 106-111.

Kumakura, M., Kasai, N., Tameda, M., Kaetu, I.. 1988. Method of pretreatment in saccharification and fermentation of waste cellulose resource. US Pat. 4: 769-082.

Leite, R.S.R., Alves-Pardo, H.F., Cabral, H., Pagnocca, F.C., Gomes, E., Silva, R. 2008. Production and characteristics comparision of crude $\beta$-glucosidases produced by microorganisms Thermoascus aurantiacus e Aureobasidium pullulans in agricultural wastes. Enzyme Microb. Technol., 43: 391-395.

Lonsane, B.K., Ghild, N.P., Budeatman, S., Ramakrishna, S.V.1985. Engineering aspects of solid state fermentation. Enzyme Microb. Technol., 7: 258-265.

Mandals, M. 1975. Microbial source of cellulose, Biotechnology and Bioengineering, 5, 81-105.

Megharaj, M., Kookana, K., Singleton, S. 1999. Activities of fenamiphos on native algal population and some enzyme activities in soil. Soil Biol. Biochem., 39: 549-1553.

Muniswaran, P.K.A., Charyulu, N.C.L.N. 1994. Solid substrate fermentation of coconut coir pitch for cellulase production. Enzyme Microb. Technol., 16: 436-440.

Muthuvelayudham, R., Viruthagiri, T. 2006. Fermentative production and kinetics of cellulose protein on Trichoderma reesei using sugarcane bagasse and rice straw. African J Biotechnol 5(20): 1873-1881.

Nandakumar, M.P., Thakur, M.S., Raghavarao, K.S.M.S., Ghilodyal, N.P. 1994. Mechanism of solid particle degradation by Aspergillus niger in solid state fermentation. Process Biochem., 29: 545-551.

Ortega, N., Busto, M.D., Perez-Mateos, M. 2000. Enzymatic saccharification of pretreated wheat straw by $T$. reesei cellulases and $A$. niger $\beta$ - 
glucosidase. Biocat Biotrans 18: $311-$ 330.

Pan XJ, Gilkes N, Kadla J, Pye K, Saka S, Ehara K, Gregg D, Xie D, Lam D \& Saddler J, Bioconversion of hybrid poplar to ethanol and co-products using an organosolv fractionation Process: Optimization of process yields. Biotechnology and Bioengineering, 94, (2006) 851-861.

Panagiotou, G., Kekos, D., Macris, B.J., Christakopoulos, P. 2003. Production of cellulolytic and xylanolytic enzymes by Fusarium oxysporum grown on corn stover in solid state fermentation. Industrial crop product, 18: 37-45.

Pandey. A., Soccol, C.R., Mitchell, D. 2000. New developments in solid state fermentation. I Process and products. Proces Biochem., 35: 1153-1169.

Park, A.R., Park, J.H., Ahn, H.J., Jang, J.Y., Yu, B.J., Um, B.H., Yoon, J.J. 2015. Enhancement of $\beta$-Glucosidase Activity from a Brown Rot Fungus Fomitopsis pinicola KCTC 6208 by Medium Optimization. Mycobiol., 43(1): 57-62.

Park, Y.S., Kang, S.W., Lee, J.S., Hong, S.I., Kim, S.W. 2002. Xylanase production in solid state fermentation by Aspergillus niger mutant using statistical experimental designs. Appl. Microbiol. Biotechnol., 58: 761-766.

Rao, M., Deshpande, N., Seeta, R., Srinivasan, M.C., Mishra, C. 1985. Hydrolysis of sugarcane bagasse by Mycelial biomass of Penicillium funiculosum. Biotechnol.
Bioeng., 27: 1070-1072.

Spiridonov, N.A., Wilson, D.B. 1998. Regulation of biosynthesis of individual cellulases in Thermomonospora fusca. $J$. Bacterio., 180: 3549-3552.

Tolan, J.S., Foody, B. 1999. Cellulsae from submerged fermentation. Advan. Biochem. Eng/Biotechnol., 65: 41-67.

Van Wyk, J.P.H., Leogale, P.B. 2001. Saccharification of waste paper mixtures with cellulase from Penicillium funiculosm. Biotechnol. Lett., 23: 184952.

Wang, Y., Xu, Y., Li, J. 2012. A novel extracellular $\quad \beta$-glucosidase from Trichosporon asahii: yield prediction, evaluation and application for aroma enhancement of Cabernet Sauvignon. $J$. Food Sci., 77: 505-515.

Yadav, J.S. 1987. Influence of nutritional supplementation on solid substrate fermentation of wheat straw with an alkaliphilic white rot fungus (Coprinus sp.). Appl. Microbiol. Biotechnol., 26: 474-478.

Zaldivar, J., Nielsen, J., Olsson, L. 2001. Fuel ethanol production from lignocellulose: a challenge for metabolic engineering and process integration. Appl. Microbiol. Biotechnol., 56(1-2):17-34.

Zhang, Y.H.P., Lynd, L.R. 2004. Toward an aggregated understanding of enzymatic hydrolysis of cellulose: Noncomplexed cellulase systems. Biotechnol. Bioeng., 88: 797-824.

\section{How to cite this article:}

Suresh Yadav, P., K. Shruthi, B.V. Siva Prasad and Subhosh Chandra, M. 2016. Enhanced Production of $\beta$-glucosidase by New Strain Aspergillus protuberus on Solid State Fermentation in Rice Husk. Int.J.Curr.Microbiol.App.Sci. 5(12): 551-564. doi: http://dx.doi.org/10.20546/ijcmas.2016.512.061 